\title{
MANAJEMEN SARANA DAN PRASARANA
}

\author{
Ahmad Sopian \\ Sekolah Tinggi Ilmu Tarbiyah Raudhatul Ulum Sakatiga \\ Email: asopian@stit-ru.ac.id
}

\begin{abstract}
Abstrak
Means are all things that can be used as a tool in achieving goals or objectives. In managing educational facilities and infrastructure, there are several principles that need to be considered so that the objectives can be achieved with a maximum of educational infrastructure are all basic completeness devices that indirectly support the implementation of the educational process in schools. The existence of educational facilities is absolutely necessary in the education process, so it is included in the components that must be met in the implementation of the education process. Without educational facilities, the education process will experience very serious difficulties, even biased education. An event that must be avoided by all parties involved in education. The function of educational facilities or infrastructure is to make students feel comfortable and can motivate students to learn, so that the learning process can run smoothly and successfully as expected, which can improve student achievent
\end{abstract}

Keywords: Management, Functions, Facilities

\section{Pendahuluan}

Sistem pendidikan merupakan rangkaian-rangkaian dari sub system atau unsur-unsur pendidikan yang saling terkait dalam mewujudkan keberhasilannya. Ada tujuan, kurikulum, materi, metode, pendidik, peserta didik, sarana, alat, pendekatan dan sebagainya. Keberadaan satu unsur membutuhkan keberadaan unsur lain, tanpa keberadaan salah satu diantara unsur-unsur itu proses pendidikan menjadi terhalang, sehingga mengalami kegagalan (Qomar, 2005: 179).

Keberadaan sarana pendidikan mutlak dibutuhkan dalam proses pendidikan, sehingga termasuk dalam komponen-komponen yang harus dipenuhi dalam pelaksanaan proses pendidikan. Tanpa sarana pendidikan, proses pendidikan akan mengalami kesulitan yang sangat serius, bahkan bias mengagalkan pendidikan. Suatu kejadian yang mesti dihindari oleh semua pihak yang terlibat dalam pendidikan.

Proses pendidikan dilaksanakan untuk mencapai suatu tujuan pendidikan. Agar tujuan pendidikan tersebut dapat dicapai maka perlu diperhatikan segala sesuatu yang mendukung keberhasilan tujuan pendidikan itu. Dari sekian faktor penunjang keberhasilan tujuan pendidikan, kesuksesan dalam proses pembelajaran merupakan salah satu faktor yang dominan. Sebab di dalam proses pembelajaran itulah terjadinya interialisasi nilai-nilai dan pewarisan budaya maupun normanorma secara langsung. Karena itu, kegiatan belajar mengajar merupakan ujung 


\section{Manajemen Sarana dan Prasarana}

\section{Ahmad Sopian}

tombak untuk tercapainya pewarisan nilai-nilai diatas. Untuk itu perlu sekali dalam proses pembelajaran itu diciptakan suasana yang kondusif agar peserta didik benarbenar tertarik dan ikut proses itu (Ramayulis, 2004: 197).

Dalam kaitannya dengan usaha menciptakan suasana yang kondusif itu sarana dan prasarana pendidikan memegang peranan yang sangat penting. Sehingga baik buruknya manajemen sarana dan prasarana pendidikan akan berpengaruh terhadap proses pembelajaran.

\section{Sarana Prasarana Pendidikan}

\section{Pengertian}

Sarana adalah segala sesuatu yang dapat dipakai sebagai alat dalam mencapai maksud atau tujuan; alat; media (Tim Penyusun Kamus Pusat Pembinaan dan Pengembangan Bahasa, 1988: 700). Menurut E. Mulyasa, Sarana Pendidikan adalah peralatan dan perlengkapan yang secara langsung dipergunakan dan menunjang proses pendidikan, khususnya proses belajar, mengajar, seperti gedung, ruang kelas, meja kursi, serta alat-alat dan media pengajaran (Mulyana, 2004: 49). Sarana pendidikan merupakan sarana penunjang bagi proses belajar-mengajar. Menurut Tim Penyusun Pedoman Pembakuan Media Pendidikan Departemen Pendidikan dan Kebudayaan, yang dimaksud dengan:

Sarana pendidikan adalah semua fasilitas yang diperlukan dalam proses belajarmengajar, baik yang bergerak maupun yang tidak bergerak agar pencapaian tujuan pendidikan dapat berjalan dengan lancar, teratur, efektif dan efisien (Arikunto, 1993: 81).

Sedangkan pengertian prasarana secara etimologis (arti kata) prasarana berarti alat tidak langsung untuk mencapai tujuan. Dalam pendidikan misalnya: lokasi/tempat, bangunan sekolah, lapangan olah raga, uang dan sebagainya. Sedang sarana seperti alat langsung untuk mencapai tujuan pendidikan, misalnya: ruang, buku, perpustakaan, laboratorium dan sebagainya (Mulyana, 2004: 40). Menurut Ibrahim Bafadal bahwa prasarana pendidikan adalah semua perangkat kelengkapan dasar yang secara tidak langsung menunjang pelaksanaan proses pendidikan di sekolah (Bafadal, 2003: 3).

Jadi, dapat disimpulkan bahwa yang dimaksud sarana pendidikan adalah semua fasilitas yang secara langsung dan menunjang proses pendidikan, khususnya proses belajar mengajar, baik yang bergerak maupun yang tidak bergerak agar pencapaian tujuan pendidikan dapat berjalan dengan lancar, teratur, efektif dan efesien. Sedangkan yang dimaksud dengan prasarana pendidikan adalah fasilitas yang secara tidak langsung menunjang jalannya proses pendidikan atau pengajaran, seperti halaman, kebun, taman sekolah, jalan menuju sekolah, tetapi dimanfaatkan secara langsung untuk proses belajar mengajar, seperti taman sekolah untuk pengajaran biologi, halaman sekolah sebagai sekaligus lapangan olah raga, komponen tersebut merupakan sarana pendidikan. 


\section{Pendayagunaan Sarana Prasarana Pendidikan}

Tujuan pendayagunaan sarana prasarana dibagi menjadi 2 bagian, yaitu tujuan umum dan tujuan khusus. Tujuan umum dari pendayagunaan sarana prasarana adalah untuk meningkatkan efektifitas dan efisiensi dalam kegiatan proses pembelajaran. Sedangkan tujuan khusus dari pendayagunaan sarana prasarana diantaranya adalah :

a. Untuk menunjang kegiatan kelas

b. Untuk mendorong dalam penggunaan dan penerapan cara-cara baru yang sesuai untuk mencapai tujuan program akademis

c. Untuk membantu memberikan perencanaan, produksi, operasional dan tindakan lanjutan untuk pengembangan sistem instruksional (Mudhoffir, 1986: 12).

Tujuan pendayagunaan sarana prasarana adalah untuk memperluas bahan pelajaran, melengkapi pelbagai kekurangan bahan dan sebagai kerangka mengajar yang sistematis (Sudjana, Rivai, 2003: 77). Perlu disadari pula bahwa pendayagunaan sarana prasarana pendidikan tersebut secara spesifik dimaksudkan

a. Untuk meletakkan konsep dasar berfikir yang konkrit dari sesuatu yang bersifat abstrak sehingga pelajaran dapat dicerna dengan mudah karena anak dihadapkan pada pengalamannya secara langsung.

b. Untuk mengoptimalkan potensi yang dimiliki oleh anak didik baik itu berupa bakat, minat, kecerdasan dan lain-lain.

\section{Prinsip-prinsip Pendayagunaan Sarana Prasarana Pendidikan}

Sarana prasarana digunakan dalam rangka upaya peningkatan atau mempertinggi mutu proses pembelajaran. Oleh karena itu diperhatikan prinsipprinsip pendayagunaannya antara lain :

a. Pendayagunaan sarana prasarana hendaknya dipandang sebagai bagian yang integral dari suatu sistem pengajaran dan bukan hanya sebagai alat bantu yang berfungsi sebagai tambahan yang digunakan bila dianggap perlu dan hanya dimanfaatkan sewaktu-waktu dibutuhkan.

b. Sarana prasarana hendaknya dipandang sebagai sumber belajar yang digunakan dalam usaha memecahkan masalah yang dihadapi dalam proses pembelajaran.

c. Guru hendaknya benar-benar menguasai teknik-teknik dari suatu sarana prasarana yang digunakan.

d. Guru seharusnya memperhitungkan untung ruginya pendayagunaan suatu sarana prasarana

e. Pendayagunaan sarana prasarana harus diorganisasi secara sistematis.

f. Jika sekiranya suatu pokok bahasan memerlukan lebih dari satu sarana prasarana maka guru dapat menggunakan sarana prasarana semaksimal mungkin sesuai dengan kebutuhan, hal tersebut digunakan agar dapat 


\section{Manajemen Sarana dan Prasarana}

\section{Ahmad Sopian}

menguntungkan dan memperlancar proses pembelajaran serta dapat merangsang siswa dalam belajar (Usman dan Asnawi, 2002: 19).

Dalam mengelola sarana dan prasarana pendidikan, terdapat beberapa prinsip yang perlu diperhatikan agar tujuan bisa tercapai dengan maksimal. Prinsipprinsip tersebut menurut Bafadal (2003) adalah :

a) Prinsip pencapaian tujuan, yaitu sarana dan prasarana pendidikan di sekolah harus selalu dalam kondisi siap pakai apabila akan didaya gunakan oleh personil sekolah dalam rangka pencapaian tujuan pembelajaran di sekolah.

b) Prinsip efisiensi, yaitu pengadaan sarana dan prasarana di sekolah harus dilakukan melalui perencanaan yang seksama, sehingga dapat diakdakan sarana dan prasarana pendidikan yang baik dengan harga yang murah. Demikian juga pemakaiannya harus dengan hati-hati sehingga mengurangi pemborosan.

c) Prinsip administratif, yaitu manajemen sarana dan prasarana pendidikan di sekolah harus selalu memperhatikan UU, peraturan, instruksi, dan petunjuk teknis yang diberlakukan oleh pihak yang berwenang.

d) Prinsip kejelasan tanggung jawab, yaitu manajemen sarana dan prasarana pendidikan di sekolah harus didelegasika kepada personel sekolah yang mampu bertanggung jawab, apabila melibatkan banyak personil sekolah dalam manajemennya, maka perlu adanya deskripsi tugas dan tanggung jawab yang jelas untuk tiap personil sekolah.

e) Prinsip kekohesifan, yaitu manajemen sarana dan prasarana pendidikan di sekolah harus direalisasikan dalam bentuk proses kerja sekolah yang sangat kompak.

\section{Macam-Macam Sarana Prasarana Pendidikan}

Pada hakikatnya proses belajar mengajar adalah proses komunikasi. Kegiatan belajar mengajar di kelas merupakan suatu dunia komunikasi tersendiri di mana guru dan siswa bertukar pikir untuk mengembangkan ide dan pengertian. Dalam komunikasi sering timbul penyimpangan-penyimpangan sehingga komunikasi tersebut tidak efektif dan efisien antara lain disebabkan oleh kecenderungan verbalisme, ketidaksiapan siswa serta kurangnya minat dan kegairahan salah satu usaha untuk mengatasi keadaan tersebut dengan penggunaan sarana prasarana pendidikan secara terintegrasi dalam proses belajar mengajar. ${ }^{1}$

Menurut Keputusan Menteri Pendidikan Nasional RI No.053/U/2001, sarana prasarana pendidikan salah satunya adalah :

\section{a Ruang}

Secara umum jenis ruang ditinjau dari fungsinya dapat dikelompokkan dalam : ruang pendidikan, ruang administrasi, dan ruang penunjang.

\section{1) Ruang pendidikan}

${ }^{1}$ Keputusan Menteri Pendidikan Republik Indonesia No. 053/U/2001 tentang Pedoman Penyusunan Standar Pelayanan Minimal Penyelenggaraan Persekolahan Bidang Pendidikan Dasar dan Menengah Menteri Pendidikan Nasional. 
Ruang pendidikan berfungsi untuk menampung kegiatan belajar mengajar teori dan praktek antara lain :
a) Ruang teori
b) Ruang laboratorium
c) Ruang olahraga
d) Ruang perpustakaan/media
e) Ruang kesenian
f) Ruang ketrampilan

\section{2) Ruang administrasi}

Ruang administrasi berfungsi untuk melaksanakan berbagai kegiatan kantor/administrasi. Ruang administrasi terdiri dari :
a) Ruang kepala sekolah
b) Ruang wakil kepala sekolah
c) Ruang guru
d) Ruang reproduksi/penggandaan
e) Ruang tata usaha

\section{3) Ruang penunjang}

Ruang penunjang berfungsi untuk menampung kegiatan yang mendukung $\mathrm{KBM}$, antara lain :
a) Ruang ibadah
b) Ruang koperasi sekolah
c) Ruang OSIS, Pramuka, PMR
d) Ruang bimbingan
e) Ruang serbaguna / umum
f) Ruang kamar mandi / WC
g) Ruang UKS

\section{b Alat dan media pendidikan}

1) Buku

1) Buku pelajaran pokok (guru dan siswa)

2) Buku pelajaran pelengkap

3) Buku bacaan

4) Buku sumber (referensi).

Ada beberapa macam sarana prasarana yang menunjang proses pendidikan atau pengajaran, antara lain : a. Laboratorium Bahasa dan Keagamaan.

Laboratorium bahasa adalah alat untuk melatih siswa untuk mendengar dan berbicara dalam bahasa asing dengan jalan menyajikan materi pelajaran yang disiapkan sebelumnya. Dalam laboratorium bahasa siswa duduk sendiri-sendiri pada bilik akuistik dan kotak suara yang telah tersedia. Siswa atau mahasiswa mendengarkan suara guru atau suara radio cassette melalui headphone. Dengan 


\section{Manajemen Sarana dan Prasarana}

\section{Ahmad Sopian}

jalan demikian siswa dapat dengan segera memperbaiki kesalahan-kesalahan yang dibuatnya (Nasution, 1999: 109-110).

Laboratorium bahasa merupakan variasi mesin mengajar yang juga menggunakan sejumlah alat audio-visual lainnya misalnya tape recorder, film strip, pelajaran berprogram dan sebagainya.

Laboratorium yang sederhana terdiri atas sejumlah "booth" atau "kotak" tempat anak belajar secara individual. Dengan memutar rekaman berisi pelajaran ia menjawab pertanyaan atau mengulangi kalimat atau lafal kata-kata, kemudian mendengarkannya kembali dan membandingkannya dengan "master tape". Rekaman jawabannya dapat dihapusnya untuk mengulangi pelajaran yang belum dikuasainya, sampai benar-benar diketahuinya.

Guru bahasa dapat berhubungan dengan tiap murid, sehingga ia dapat mengontrol kemajuan tiap murid dan bila perlu mengajukan pertanyaan kepadanya atau menjawab pertanyaan murid dan memberi penjelasan yang diperlukan.

Anak-anak bisa belajar sendiri dan bila absen beberapa waktu dapat melanjutkannya tanpa terikat pada kemajuan murid-murid lain. Jadi dengan laboratorium bahasa setiap murid dapat belajar secara individual menurut kecepatan masing-masing dan bila perlu mendapat bantuan guru secara pribadi.

Mesin belajar dan laboratorium bahasa mahal dan seperti alat elektronik lainnya dapat rusak, sehingga memerlukan reparasi dari ahli teknik yang khusus. Namun yang paling penting mengenai alat teknologi pendidikan bukan hanya soal harganya, melainkan ketrampilan guru untuk menggunakannya bagi peningkatan mutu pendidikan. Makin tinggi teknologi, makin tinggi pula ketrampilan yang dituntut dari guru (Depag RI, 2002: 34).

Selain laboratorium bahasa, ada juga laboratorium keagamaan. Laboratorium yang dimaksud adalah tempat yang layak sebagai sentral kegiatan pembinaan keagamaan, seperti : masjid (sebagai laboratorium pembinaan shalat berjamaah dan latihan menjadi khatib, laboratorium pembinaan manasik haji), serta sarana dan prasarana lainnya yang bisa dipakai untuk kegiatan ritual keagamaan lainnya, seperti untuk praktek penyembelihan hewan qurban, upacara pernikahan, mengurusi mayat, dan lain-lain. Semua kegiatan atau praktek kegiatan yang sering dijalan dalam masyarakat Islam ini harus diajarkan kepada para siswa sekolah di Indonesia supaya mereka mampu bersosialisasi dengan mudah, dan bahkan jika mereka menjadi pemimpin umat di daerahnya atau di lingkungan masyarakatnya mereka tidak merasa asing melihat atau menyaksikan kegiatan-kegiatan keagamaan seperti ini (Syukur, 2005: 97).

\section{2) Perpustakaan sekolah}

Perpustakaan sebagai pusat sumber belajar memiliki peran sangat penting dalam proses belajar mengajar. Salah satu fungsi perpustakaan adalah bertujuan untuk memotivasi pada siswa agara lebih giat membaca. Membaca merupakan modal utama untuk mencapai kewajiban akademik dan perpustakaan menjadi sarana yang paling vital dalam hal ini (Syukur, 2005: 97). 
Perkembangan perpustakaan saat ini menunjukkan bahwa perpustakaan bukan hanya merupakan tempat untuk menyimpan atau mengoleksi buku sebagai benda mati. Perpustakaan saat ini harus sebagai tempat yang disebut "the prevention of knowledge". Artinya perpustakaan merupakan tempat untuk mengumpulkan memelihara dan mengembangkan ilmu pengetahuan. Secara khusus perpustakaan berfungsi sebagai tempat pengumpulan, pelestarian, pengelolaan, pemanfaatan dan penyebarluasan informasi.

Perpustakaan berasal dari kata dasar pustaka, pustaka berarti buku. Juga menimbulkan istilah turunan lain seperti bahan pustaka, pustakawan, kepustakaan, dan ilmu pengetahuan. Pustaka telah dikenal manusia sejak tahun $500 \mathrm{M}$. Bahanbahan itu disimpan, diolah dan disebarluaskan melalui sebuah pranata yang dibentuk khusus untuk keperluan itu yang disebut kepustakaan. Dalam perkembangannya tumbuh pula pranata lain yang kegiatannya mirip bahkan tumpang tindih dengan perpustakaan, antara lain dokumentasi dan arsip-arsip.

Peranan perpustakaan selaku mata rantai kunci dalam proses belajar mengajar menjadikan salah satu bagian yang amat penting dari sekolah. Perpustakaan yang baik menyediakan sumber-sumber belajar yang terpusat yang akan memenuhi dengan efisiensi kebutuhan-kebutuhan disetiap bagian pengajaran dan pelayanan di sekolah (Sutisna, 1986: 27).

Pada umumnya sekolah-sekolah kita baru menyediakan pelayanan perpustakaan yang sangat minimal bagi murid-murid. Bahkan banyak diantara mereka yang tidak memiliki pelayanan perpustakaan apapun. Dalam keadaan serupa itu murid harus menambah informasi dalam buku-buku pelajaran wajib melalui perpustakaan umum, sejauh itu tersedia di tempat mereka bersekolah. Untunglah bahwa akhir-akhir ini ada usaha untuk menggiatkan sekolah-sekolah dalam mengembangkan perpustakaan mereka (Syukur, 2005: 102).

Dari kajian tentang kelengkapan perpustakaan yang pokok seperti tersebut di atas, maka pengertian perpustakaan adalah suatu unit kerja yang berupa tempat mengumpulkan, menyimpan dan memelihara koleksi bahan pustaka yang dikelola dan diatur secara sistematis dengan cara tertentu, untuk digunakan untuk digunakan secara kontinyu oleh pemakaiannya sebagai sumber informasi (Rahardjo, 1998: 268).

\section{3) Media pengajaran}

Kata media berasal dari bahasa latin, merupakan bentuk jamak dari medium yang secara harfiah berarti perantara atau pengantar. Istilah media bisa diartikan sebagai bentuk-bentuk komunikasi cetak dan audiovisual serta teknologi komunikasi lainnya(Syukur, 2005: 125). Kemp dan Dayton mengemukakan peran media dalam proses komunikasi sebagai alat pengirim (transfer) yang mentransmisikan pesan dari pengirim (sender) kepada penerima pesan atau informasi (receiver). Ada juga yang mendefinisikan media sebagai teknik yang digunakan dalam rangka lebih mengefektifkan komunikasi antara guru dan murid 


\section{Manajemen Sarana dan Prasarana}

\section{Ahmad Sopian}

dalam proses pendidikan dan pengajaran di sekolah (Daradjat, 1995: 226). Media pendidikan mengandung aspek-aspek, sebagai alat dan sebagai, teknik yang berkaitan erat dengan metode mengajar (Syukur, 2005: 97).

Dari uraian di atas nampak jelas peran media pengajaran merupakan sebagai perantara atau alat untuk memudahkan proses belajar mengajar agar tercapai tujuan pengajaran secara efektif dan efisien. Jika diambil formasi pendapat di atas media pengajaran adalah alat atau metodik dan teknik yang digunakan sebagai perantara komunikasi antara seorang guru dan murid dalam rangka lebih mengefektifkan komunikasi dan interaksi antara guru dan siswa dalam proses pendidikan pengajaran di sekolah (Daradjat, 1995: 234). Media pendidikan harus digunakan dengan amat berhati-hati dan guru harus waspada terhadap keterbatasanketerbatasan penggunaannya (Rahardjo, 1998: 270).

Pada mulanya media hanya berfungsi sebagai alat bantu yang memperlancar dan mempertinggi proses belajar mengajar. Alat bantu tersebut dapat memberikan pengalaman yang mendorong motivasi belajar, memperjelas dan mempermudah konsep yang abstrak, menyederhanakan teori yang komplek dan mempertinggi daya serap atau retensi belajar.30 Dewasa ini dengan perkembangan teknologi serta pengetahuan, maka media pengajar berfungsi sebagai berikut:

1) Membantu memudahkan belajar bagi siswa dan juga memudahkan pengajaran bagi guru.

2) Memberikan pengalaman lebih nyata (abstrak menjadi konkrit).

3) Menarik perhatian siswa lebih besar (jalannya tidak membosankan).

4) Semua indera murid dapat diaktifkan.

5) Lebih menarik perhatian dan minat murid dalam belajar.

Dalam buku E. Stone, Readings in Educational Psychology Learning and Teaching, mengungkapkan pentingnya media pengajaran antara lain :

1) An ordered sequence of stimulus items

2) Specific student response

3) Immediate knowledge of result

4) Small steps

5) Minimum steps

6) Gradual shaping of terminal behavior

7) Self pacing.

Artinya :

1) Rangkaian pesan sebagai perangsang berita

2) Siswa lebih spesifik dalam menanggapi

3) Hasil dari pengetahuan dapat segera diketahui

4) Langkah-langkah kecil

5) Dapat meminimumkan kesalahan

6) Tingkah laku dapat dibentuk berangsur-angsur

7) Dengan sendirinya dapat mengikuti zaman. 


\section{4) Prasarana pendidikan}

Prasarana pendidik banyak terdapat di setiap sekolah seperti halaman, kebun, taman sekolah, jalan menuju sekolah, tetapi jika dimanfaatkan secara langsung untuk proses belajar mengajar, seperti taman sekolah untuk pengajaran biologi, halaman sekolah sebagai sekaligus lapangan olah raga, komponen tersebut merupakan sarana pendidikan (Stone, 1970: 331-332).

\section{Fungsi Pendayagunaan Sarana Prasarana Pendidikan}

Menurut Oemar Hamalik mengutip dari buku Encyclopedia of Educational Research mengungkapkan bahwa fungsi dari pendayagunaan sarana prasarana pendidikan adalah:

1. Meletakkan dasar-dasar yang konkret untuk berpikir, oleh karena itu mengurangi verbalisme.

2. Memperbesar perhatian para siswa

3. Meletakkan dasar-dasar yang penting untuk perkembangan belajar

4. Memberikan pengalaman yang nyata yang dapat menumbuhkan kegiatan berusaha sendiri di kalangan siswa

5. Menumbuhkan pemikiran yang teratur dan continue

6. Membantu tumbuhnya pengertian, dengan demikian membantu perkembangan kemampuan berbahasa.

7. Memberikan pengalaman-pengalaman yang tidak mudah diperoleh dengan cara lain (Mulyana, 1998: 49).

Perlu juga ditegaskan bahwa pendayagunaan sarana prasarana adalah sama halnya dengan sarana prasarana pembelajaran lainnya, artinya sarana prasarana dapat digunakan untuk pendidikan agama. Jika aktivitasnya diwarnai dengan ajaran-ajaran agama Islam.

\section{Simpulan}

Prasarana pendidikan merupakan semua komponen yang secara tidak langsung menunjang jalannya proses belajar mengajar di sekolah atau perangkat kelengkapan dasar yang secara tidak langsung yang menunjang proses pendidikan di sekolah. Sedangkan sarana adalah semua perangkat peralatan, bahan dan perabot yang secara langsung digunakan dalam proses pendidikan atau alat langsung untuk mencapai tujuan pendidikan.

Fungsi fasilitas atau sarana prasarana pendidikan adalah membuat siswa merasa nyaman dan dapat memotivasi siswa dalam belajar, sehingga proses belajar dapat berjalan dengan lancar dan berhasil sesuai yang diharapkan yaitu dapat meningkatkan prestasi siswa. 
Basyiruddin Usman dan Asnawi, Media Pembelajaran, Jakarta: Ciputat Pers, 2002

Depag RI, Kendali Mutu Pendidikan Agama Islam, Jakarta : Direktorat Jendral Pembinaan Kelembagaan Agama Islam / Direktorat Pembinaan Pendidikan Agama Islam Pada Sekolah Umum Negeri, 2002

E. Stone, Readings in Educational Psychology Learning and Teaching, London : Methuen and Co. Ltd, 1970

E. Mulyasa, Manajemen Berbasis Sekolah, Bandung: PT Remaja Rosdakarya, 2004, Cet. VII

Fatah Syukur NC, Teknologi Pendidikan, Semarang: RaSAIL bekerjasama dengan Walisongo Press, 2005

Ibrahim Bafadal, Seri Manajemen Peningkatan Mutu Pendidikan Berbasis Sekolah, Manajemen Perlengkapan Sekolah Teori dan Aplikasi, Jakarta: PT Bumi Aksara, 2003

Keputusan Menteri Pendidikan Republik Indonesia No. 053/U/2001 tentang Pedoman Penyusunan Standar Pelayanan Minimal Penyelenggaraan Persekolahan Bidang Pendidikan Dasar dan Menengah Menteri Pendidikan Nasional

M. Daryanto, Administrasi Pendidikan, Jakarta: PT. Rineka Cipta, 2006, Cet. IV

Mudhoffir, Prinsip-Prinsip Pengelolaan Pusat Sumber Belajar, Bandung : CV. Remaja Rosdakarya, 1986

Mujamil Qomar, Epistemologi Pendidikan Islam dari Metode Rasional Hingga Metode Kritik, Jakarta: Erlangga, 2005

Nana Sudjana, Ahmad Rivai, Teknologi Pengajaran, Bandung : Sinar Baru Algensindo, 2003

Otong Sutisna, Administrasi Pendidikan, Bandung: Angkasa, 1986

Rahardjo, "Media Pendidikan", dalam Chabib Thoha (eds.), PBM-PAI di Sekolah; Eksistensi dan Proses Belajar Mengajar Pendidikan Agama Islam, Yogyakarta: Pustaka Pelajar bekerjasama dengan Fakultas Tarbiyah IAIN Walisongo Semarang, 1998

Ramayulis, Ilmu Pendidikan Islam, Jakarta: Kalam Mulia, 2004

S. Nasution, Teknologi Pendidikan, Jakarta : Bumi Aksara, 1999, Cet. 2

Suharsimi Arikunto, Organisasi dan Administrasi Pendidikan Teknologi dan Kejuruan, Jakarta: PT GrafindoPersada, 1999, Cet. II 
RAUDHAH Proud To Be Professionals qurnal Tarbiyah? damiyak

Volume 4 Nomor 2 Edisi Desember 2019

P-ISSN : 2541-3686

Tim Penyusun Kamus Pusat Pembinaan dan Pengembangan Bahasa, Kamus Besar Bahasa Indonesia, Jakarta: Balai Pustaka, 1988

Zakiah Daradjat, Metodik Khusus Pengajaran Agama Islam, Jakarta: Bumi Aksara Bekerjasama dengan Direktorat Jenderal Pembinaan Kelembagaan Agama Islam Departemen Agama, 1995. 
Manajemen Sarana dan Prasarana

Ahmad Sopian 